Next, unfasten the bullet forceps from the cervix, allowing it to go back as you roll the body of the uterus forward into the vagina or at least into plain view. If there are no adhesions, the uterus comes forward without force. If there are adhesions they are easily reached with the fingers and separated.

The round ligament is the first cord in sight and can be seen, examined and differentiated from ligamentum proprium and Fallopian tube. The ligament is seized from one to two inches from the horn of the uterus, with bullet forceps and drawn out, thus necessarily doubliny it upon itself. With medium sized silk, its approximating doubled surfaces are sewed together. By thus folding it upon itself by the use of three or four stitches, the round ligament can be shortened from six to nine centimeters.

The other round ligament is treated in like manner, and thus the uterus is held up and anteverted. The stitches holding the peritoneum to vagina are now cut and the two peritoneal surfaces re-united. The transverse incision at the utero-vaginal junction is then sewed vertically thus lengthening the anterior vaginal wall, and shoving the cervix back.

A little gauze is placed in the vagina and the operation is finished, in most cases without having tied a blood vessel, and unless the wound has been infected, without danger.

There is no danger of injuring the ureters, if the. operation is done as described above, as they are shoved out of the way. In cases where there is a relaxed vagina and an anterior colporrhaphy is needed, instead of making the transverse incision, an elliptic piece can be removed from the anterior vaginal wall, and the bladder separated from the uterus directly under the eye. The round ligaments are treated as in the first case. In sewing up the vaginal wall you have, of course, done an anterior colporrhaphy.

This operation was first made by $\mathbf{E}$. Wertheim of Vienna, in January, 1896, and his first publication of the same appeared in the Centralblatt für Gynäkologie in February, 1896, since which time it has been performed about twenty-five times and with perfect results.

Its advantages over the Alexander-Adams operation are: 1 , it leaves no visible 'scar; 2 , the operation is easier to perform, the ligaments being larger at this point and easy to find; 3 , the transverse cut in the vagina, sewed vertically, assists in anteverting the uterus; 4 , it allows perfect access to the pelvic viscera, thus permitting of minor repairing at the same sitting, when indicated; 5, the operation is less dangerous.

Its advantages over any method of anterior fixation which will prevent the free growing of a gravid uterus are very apparent. The bladder is left in its normal position. A subsequent pregnancy will not be hindered, as the shortened ligaments can stretch as in the normal state. That every antefixation which will prevent the free growing of a gravid uterus is likely to be the source of danger, is well illustrated in Miländer's report (Zeitschrift für Geburtshülfe und Gynäkologie. Bd. xxxiii, Hftt. 3). In fifty-four cases of full term labor after ventrofixation, eleven were operative, four forceps, two Cæsarean sections, four turning and one extraction.

The uterus is not only anteverted, but it is held up, as one can very easily prove by doing the operation upon the cadaver, and the organ is not antefixed, but held in its normal position by its normal attachments.
This operation I have witnessed frequently in Schauta's operating room, and the ease and rapidity with which it is done, beside its many advantages over other known methods, is my excuse for sending this report.

For the past year, I have not had access to any medical journal except the Journal of THE AMERICan Medical Association, hence if this method of E. Wertheim's has been reported in an American medical journal, I am ignorant of the fact.

\section{A NEW APPARATUS FOR FRACTURE OF THE CLAVICLE.}

BY EVAN O'NEILT KANE, M.D. KANE, PENN.

The treatment for fracture of the clavicle is almost uniformly unsuccessful. Were it not that the resulting rounded shoulder, narrowed chest and bone deformity do not materially injure the patient, the best surgeons would be continually mulcted in malpractice suits.

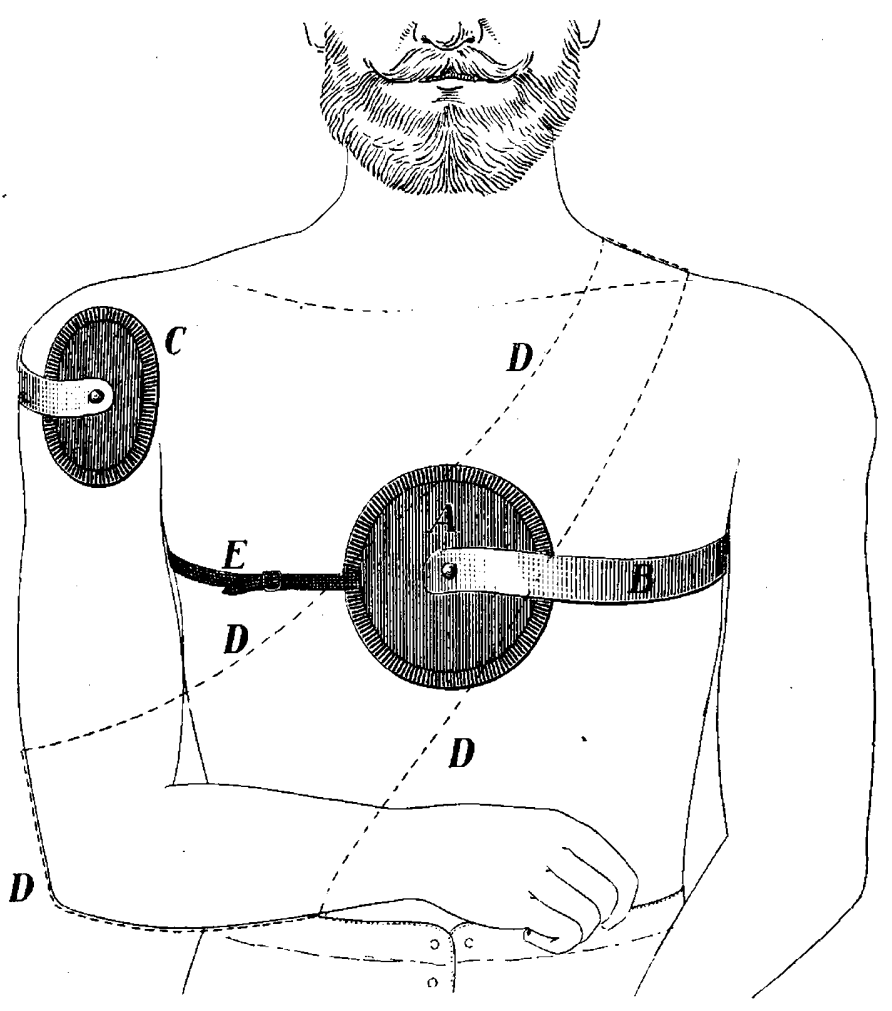

Front. A, chest pad; B, spring on sound side; C, shoulder pad and spring on injured side; $D$, dotted lines indicating ordinary sling; $E$, elastic strap and buckle.

It is true that if the patient can be placed for three or four weeks upon his back; a narrow cushion below and a shot.bag above, a perfect result may be obtained; but few can bear with so irksome a treatment for so comparatively trivial an injury. No other methods of treatment produce perfect results; and all are painful or even prejudicial to the patient's health. Many of these apparatus are now discarded as cumbrous, complicated and unsatisfactory. the pad in the axilla sooner or later exerts so much pressure upon the nerves and vessels as to require its removal. Bandaging the arm across the chest, rarely attains more than fixation and the prevention of falling of the shoulder, while it so cramps the arm and constricts 
the chest as, to make it unbearable for sensitive patients.

The plaster of paris figure of eight and the adhesive plaster dressing are fairly satisfactory, if they can be endured, but they are, especially in warm weather, very difficult to be borne for more than a few days, and when removed the arm on the injured side is sometimes so paralyzed, swelled or cramped as to be nearly useless for a number of days, while, the results are not perfect in either case.

The displacement in fracture of the clavicle may generally be stated as occurring inward, forward and downward, while on account of the difficulty of overcoming the shortening incident upon muscular contraction considerable over-riding is present.

On account of the difficulty of obtaining a proper point d'appui but one of the deformities is ever completely obviated, i.e., the downward displacement

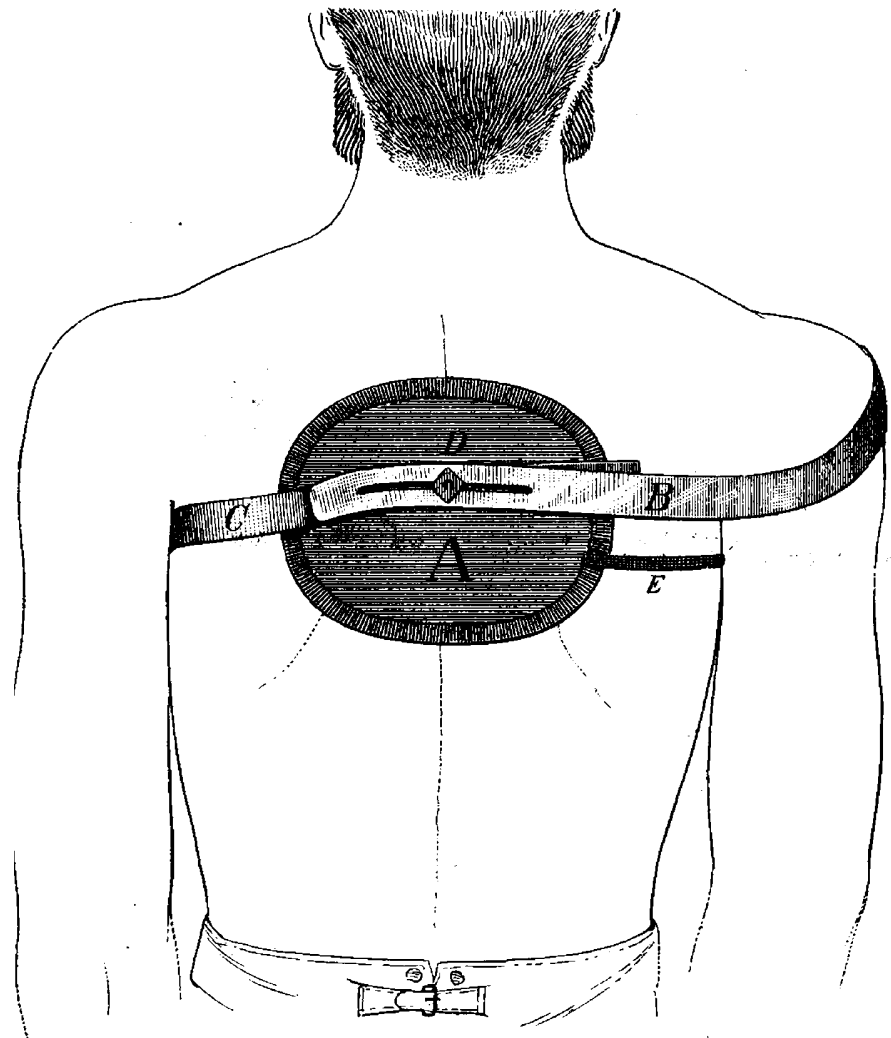

Back. A, back pad; B, spring passing forward around injured shoulder to terminate in front in small shoulder pad; $C$, spring passing around chest on sound side to terminate in lurge pad on middle of chest; $D$, set screw and slot in spring; E, elastic strap.

usually rectified by some form of sling. I am omitting the treatment by dorsal decubitus.

By my spring-lever apparatus and a sling I believe I have obviated all the difficulties formerly met, securing to my patients fair motion of the thorax and comparative freedom to the hand and arm of the injured side; a perfect co-aptation of the fragments; freedom from shortening and practically no deformity with a minimum of discomfort. My device consists of a combination of springs and pads with an elastic strap. The springs, two in number, are fastened, one on each side, by a screw bolt to a large pad behind, each terminating in front in another.

. One pad, large and circular, acts as a counter pressure upon the chest from in front; the other, a smaller one at the termination of the spring on the injured side, is arranged to press upon the anterior surface of that shoulder. Thus the spring passing from the back pad around the sound side to the chest pad holds the whole apparatus in position, although, allowing full play to the respiratory muscles, while the spring passing from the same position behind, around forward and over the shoulder on the injured side, by its continued traction backward drags the shoulder with it, prevents over-riding or angular deformity of the bone and yet allows motion. The elastic strap though not necessary is an additional security against sliding of the apparatus. It is fastened to the back pad and passes around the thorax on the injured side to be attached to the chest pad in front, and with quiet patients can often be dispensed with.

The same result is attained and maintained permanently when the apparatus is in position as that transiently produced by the surgeon when he grasps the shoulder and draws it backward in setting the bone; and which he is unable to retain with his dressings when he relinquishes his grasp unless he places his patient in the dorsal decubitus.

In addition, an ordinary sling is required in order to keep the shoulder from falling, but this does not cause any discomfort. The apparatus, which can be taken off or put on as readily as the simplest rupture truss, may be removed every night when the patient retires. He must then, however, lie upon his back, preferably along a narrow cushion. This he is glad to do on account of the additional freedom and comfort afforded. It requires no skill on the part of the attendant to replace the apparatus when the patient arises in the morning.

This contrivance may readily be constructed with a combination of slots and set screws to enable it to. serve for either right or left side and for various breadths of shoulders.

In my hands it has been productive of perfect results, as well as affording far less discomfort than any other method of treatment which I have adopted and, though more expensive than ordinary bandages and adhesive plaster, it pays both surgeon and patient amply for the slight extra expense in the comfort it affords, and the freedom from deformity which follows its use.

\section{SOME UNUSUAI CONGENITAL DEFORMITIES.}

Read before the Tenth Annual Meeting of the American Orthopedic Association, at Buffalo, May 18-20, 1896 .

BY JOHN RIDLON, M.D.

Professor of Orthopedic Surgery, Northwestern University Medica School; Senior Orthopedic surgeon to St. Luke's and Michael Reese Hospitals, and Surgeon-in-charge of the Home for Crippled Children, Chicago.

Believing it to be the duty of a specialist to present a record of unusual cases to his associates, I beg to offer for your consideration a brief report of the following cases that have come under my observation during the past three years.

Case 1. Congenital constriction bands, etc.-H. D., male, $21 / 2$ years old, the first child of healthy parents. There is no physical defect or deformity in the family for at least three generations. The pregnancy and birth were uneventful and in all respects normal. The mother is unable to offer any suggestions as to a possible cause for the deformities.

Left hand: The index finger was joined (webbed) to the ring finger, and the ring finger to the little finger from the tips nearly to the junction of the proximal and middle phalanges; and the middle finger was amputated at the end of the proximal phalanx and was pointed (conical). Otherwise the hand was normal. 